\title{
BMJ Open Association between reported sleep need and sleepiness at the wheel: comparative study on French highways between 1996 and 2011
}

\author{
M A Quera-Salva, ${ }^{1,2}$ S Hartley, ${ }^{1}$ R Sauvagnac-Quera, ${ }^{3} \mathrm{P}$ Sagaspe, ${ }^{4} \mathrm{~J}$ Taillard, ${ }^{4}$ \\ B Contrand, ${ }^{5,6} \mathrm{~J} \mathrm{~A} \mathrm{Micoulaud,}{ }^{5}$ E Lagarde, ${ }^{5,6} \mathrm{~F} \mathrm{Barbot}^{2}{ }^{2} \mathrm{P}$ Philip ${ }^{4}$
}

To cite: Quera-Salva MA, Hartley S, SauvagnacQuera $\mathrm{R}$, et al. Association between reported sleep need and sleepiness at the wheel: comparative study on French highways between 1996 and 2011. BMJ Open 2016;6: e012382. doi:10.1136/ bmjopen-2016-012382

- Prepublication history for this paper is available online. To view these files please visit the journal online (http://dx.doi.org/10.1136/ bmjopen-2016-012382).

Received 9 May 2016 Revised 26 September 2016 Accepted 3 October 2016
CrossMark

For numbered affiliations see end of article.

Correspondence to Dr M A Quera-Salva; ma.quera@aphp.fr.

\section{ABSTRACT}

Objective: To investigate the evolution over 15 years of sleep schedules, sleepiness at the wheel and driving risk among highway drivers.

Methods: Comparative survey including questions on usual sleep schedules and before the trip, sleepiness at the wheel, the Epworth sleepiness scale, Basic Nordic Sleep Questionnaire (BNSQ) and a travel questionnaire.

Results: $80 \%$ of drivers stopped by the highway patrol agreed to participate in both studies with a total of 3545 drivers in 2011 and 2196 drivers in 1996 interviewed. After standardisation based on sex, age and mean annual driving distance, drivers in 2011 reported shorter sleep time on week days $(p<0.0001)$, and week-ends $(p<0.0001)$ and shorter optimal sleep time $(p<0.0001)$ compared to 1996 drivers. There were more drivers sleepy at the wheel in 2011 than in 1996 $(p<0.0001)$ and 2.5 times more drivers in 2011 than in 1996 had an Epworth sleepiness score $>15$ indicating severe sleepiness.

Conclusions: Even if drivers in 2011 reported good sleep hygiene prior to a highway journey, drivers have reduced their mean weekly sleep duration over 15 years and have a higher risk of sleepiness at the wheel. Sleep hygiene for automobile drivers remains an important concept to address.

\section{INTRODUCTION}

Sleepiness at the wheel is a major international public health issue, as sleepiness at the wheel is an important factor contributing to the burden of traffic-related morbidity and mortality. ${ }^{1-4}$ Road traffic accidents are the main cause of mortality and a severe handicap in the under 29 years and the 9th cause of mortality for all ages. ${ }^{5}$ The economic cost of road insecurity in 2009 in Europe was $€ 130$ billion. $^{5}$

Published estimates of the proportion of road traffic accidents attributable to sleepiness range from $3 \%, 10 \%$ to $33 \%$ according to

\section{Strengths and limitations of this study}

- Comparative study to explore the evolution of drivers' sleep-related behaviour over a 15-year period study using identical methodology and large sample size.

- Important findings relating to sleep hygiene with relevance to future road safety campaigns.

- Study in 1996 and 2011 performed in different regions of France but population homogenized using a direct standardization method.

- Interviews performed between 08:00 and 20:00 with possible underestimate of the frequency of sleep-deprived drivers.

studies conducted in the USA,${ }^{6}$ France, ${ }^{7}$ and New Zealand ${ }^{2}$ over the past 15 years. In France, sleepiness in drivers was responsible for $37 \%$ of fatal accidents on the motorway network in 2013 and excessive sleepiness is currently the leading cause of fatal accidents in the French highway network, followed by excessive speeding, alcohol, drugs and medicine consumption. ${ }^{8}$ Many factors intervene in reducing vigilance: sleep deprivation, poor sleep, time of day, fatigue, excessive driving time, sedating drugs and medical conditions. The risks of sleepiness are magnified by highway driving as it is a monotonous task: drivers' ability to react to unpredictable events deteriorates when exposed to a highly predictable and uneventful driving task, ${ }^{9} 10$ and the consequences of inattention are severe.

French road safety campaigns are run annually at a national level by the French Government. Information is diffused via national media and across the entire highway network including on large illuminated signs placed over the highway. Campaigns initially targeted excessive speed and alcohol use, but during the past 15 years (since the publication of the 1996 study) have increasingly 
focused on the need for drivers to respect their sleep needs, advising adequate rest before a long trip, taking breaks during driving and avoidance of starting trips during the night. Efforts have been made to reduce the monotony of long drives with the provision of information signs and rest areas.

We previously reported an observational study among a large sample of highway drivers showing that acute sleep loss no longer explained sleepiness at the wheel. Non-restorative sleep helped to explain near-miss sleepy accidents (NMSA) more adequately than acute sleep loss. ${ }^{11}$

In the present study we investigate the effects of the past 15 years of public road safety campaigns concerning sleepiness and accident risk among highway drivers by comparing the evolution of drivers' behaviour between two observational studies performed in France with the same methodology.

\section{METHODS}

This comparative study aimed to evaluate the evolution of sleep hygiene and sleep deprivation among highway drivers between 2011 and $1996 .{ }^{7}$ Both studies were performed under identical conditions, using the same methodology, at motorway toll booths.

Both studies were performed in July during the summer vacation and departure period between 08:00 and 20:00 at toll booths. Drivers who stopped at the toll booths when one of the interviewers was available were approached by the highway patrol and asked to participate in the study. Investigators informed participants of the study and sought consent. Participants were informed that the study was anonymous and would take no more than $15 \mathrm{~min}$. They were reassured that it was independent of the highway patrol and that they could refuse to participate if they wished. Drivers with comprehension difficulties were excluded. Trained investigators administered a structured interview, which was recorded on paper in 1996 and electronically (iPad2) in 2011.

Each driver, with the help of the interviewer, filled out an eight-point scale evaluating overall daytime alertness, the Epworth sleepiness scale and a validated questionnaire exploring the usual sleep schedule of the drivers as well as the presence of sleep disorders, the Basic Nordic Sleep questionnaire (BNSQ). All questionnaires had been used previously in the 1996 survey published in $1999 .{ }^{9}$ In addition, visual analogue scales on subjective sleepiness at the moment of the interview were completed. Participants were asked about their total sleep time during the previous 24 hours, during the week and during weekends.

\section{Measurements}

For each participant, the following data were collected: sex; age; self-reported weight and height; marital status; driving distance; use of alcohol, cigarettes; coffee; other caffeinated beverages; sleeping pills and stimulant medication (eg. methylphenidate) consumption. We also collected the estimated sleep needs and total sleep time in the 24 hours before starting the journey as well as the usual sleep time during the workweek and on weekends from the drivers. Sleep time was divided into three categories: $<7$ hours, between 7 and 8 hours $59 \mathrm{~min}$, and 9 and more hours. In addition the participants provided information on sleepiness and subjective sleep symptoms during the past 3 months with help from the interviewers by completing the Epworth sleepiness scale, ${ }^{12}$ the BNSQ ${ }^{13-15}$ and a $10 \mathrm{~cm}$ visual analogue scale for subjective sleepiness at the time of interview (from 0 very sleepy to 10, not sleepy at all). The Epworth sleepiness score were divided into three categories $(<11,11-$ $14, \geq 15)$. The BNSQ uses a five-point scale $(1$, never or less than once a month; 5 , every night or almost every night) to determine how often a symptom occurs. For this analysis we converted each BNSQ response to a binary (yes or no) variable by defining $<1$ a week (score 1 and 2), 1-2 days a week (score 3) and 3 or more days a week (score 4 and 5). A sleepiness-related driving accident in the past year was measured by binary response (yes or no) to: 1: never, 2: sleepiness not interfering with driving, 3: sleepiness requiring the driver to stop and 4: sleepiness leading to a near-miss accident (NMA). Finally, times of departure were divided into four categories (midnight to 05:59, 06:00-11:59; 12:00$17: 59 ; 18: 00-23: 59)$.

\section{Statistics}

The 2011 data and 1996 data were collated in the same database. Continuous variables were expressed as Mean $\pm \mathrm{SD}$, and categorical variables were expressed as relative frequencies. Between-group comparisons with the Mann-Whitney U-test for continuous variables or $\chi^{2}$ test for categorical variables were used to compare demographic, clinical and driving habits characteristics in both populations. Statistical analyses were performed with software SAS. A p value of 0.05 or less was considered as significant.

As shown in table 1, the 1996 population was younger, more likely to be male and their driving distance was longer than the 2011 population. A direct standardisation method was used for comparisons of these two groups. The 2011 data were standardised to the joint distribution in the 1966 of sex, age (16-30, 31-49, 50 years and more) and driving distance (99 and less, 100-300, $301-500,501 \mathrm{~km}$ and more). The standardised estimate for the 2011 population is interpreted as the mean/frequency that would have been obtained if the 2011 population had the same distribution of the confounding variable as the 1996 population.

Reporting followed international STROBE guidelines. ${ }^{16}$

\section{RESULTS}

A total of 499624 cars in 2011 and 214263 cars in 1996 went through the toll booths during the study periods. Eighty per cent of drivers stopped by the highway patrol 
Table 1 Demographic characteristics and driving distance

\begin{tabular}{|c|c|c|c|}
\hline Variables & $\begin{array}{l}1996 \\
N=2197\end{array}$ & $\begin{array}{l}2011 \\
N=3558\end{array}$ & p Value \\
\hline $\begin{array}{l}\text { BMI ((weight }(\mathrm{kg}) / \\
\left.\text { height }^{2}(\mathrm{~cm})\right)\end{array}$ & & & $<0.0001$ \\
\hline Mean $\pm S D$ & $24.4( \pm 3.4)$ & $25.1( \pm 3.9)$ & \\
\hline Sex & & & $<0.01$ \\
\hline Male & 1711 (77.9) & $2658(74.7)$ & \\
\hline Female & 485 (22.1) & 900 (25.3) & \\
\hline Age (years) & & & $<0.0001$ \\
\hline $16-30$ & 442 (20.1) & 406 (11.4) & \\
\hline $31-49$ & 1099 (50.0) & $1734(48.7)$ & \\
\hline 50 and more & 656 (29.9) & 1418 (39.9) & \\
\hline Driving distance & & & $<0.0001$ \\
\hline Mean $\pm S D$ & $377( \pm 297)$ & $337( \pm 230)$ & \\
\hline $\begin{array}{l}\text { Driving distance } \\
(\mathrm{km})\end{array}$ & & & $<0.0001$ \\
\hline-100 & $483(24.1)$ & 254 (7.1) & \\
\hline $100-300$ & $514(25.6)$ & 1940 (54.5) & \\
\hline $301-500$ & $333(16.6)$ & $820(23.1)$ & \\
\hline+500 & 677 (33.7) & $544(15.3)$ & \\
\hline
\end{tabular}

Driving remains a male-dominated task, but there were fewer single drivers in 2011 than in $1996\left(\chi^{2} p<0.001\right)$

BMI, body mass index.

agreed to participate in the study with a total of 3545 in 2011 and 2196 in 1996.

\section{Driver's characteristics}

The drivers' demographic characteristics' were slightly different in both studies (see table 1). Drivers were younger in the 1996 than in 2011 study. They were predominately men but the sex distribution was different with fewer women in the 1996 than in 2011 study. Driving distance was shorter in 2011 than 1996 at the moment of the interview.

\section{Sleep habits characteristics}

Duration of sleep during week days and during the week-end was shorter in 2011 than in 1996. However, the duration of sleep was similar in both studies the night just before the trip. Daytime napping was more common in 2011 (18.4\%) than in 1996 (14.8\%; table 2).

During the 3 months preceding the study, as measured by the BNSQ, fewer drivers considered their sleep refreshing in 2011 compared to 1996, more drivers considered themselves sleepy during the daytime in 2011 than in 1996 and there were more snorers in 2011 than in 1996.

\section{Sleepiness at the wheel}

The percentage of drivers sleepy at the wheel during the trip was higher in 2011 than in 1996. Over twice as many drivers had to stop because of sleepiness in 2011 compared to 1996, and seven times more drivers experienced a NMSA in 2011 than in 1996. At the same time there were 2.5-fold more drivers in 2011 than in 1996 with an Epworth sleepiness score $>15$ indicating chronic sleepiness, while instantaneous sleepiness at the moment of the interview, as measured by visual analogue scales was similar in both studies (table 3 ).

\section{The trip and consumptions}

As can be seen in table 4 more drivers stopped for a break during the trip and for longer periods in 1996 than in 2011, and more drivers took a nap during stops in $1996(13.1 \%)$ than in $2011(6.8 \%)$. Consumption of stimulant medication and cigarette smoking was higher in 1996 than in 2011, but the use of caffeinated drinks, coffee or tea was higher in 2011 than in 1996.

\section{Time of departure}

There were nearly twofold more drivers starting the trip between midnight and 06:00 in 1996 than in 2011 (table 5).

\section{DISCUSSION}

This comparative study shows that drivers in 2011 had reduced their sleep time and were sleepier than 1996 drivers. In 2011 there were 21/2 times more drivers suffering from severe sleepiness and seven times more drivers having suffered a NMA than in1996. To the best of our knowledge, our study is the first to explore the evolution of drivers' sleep-related behaviour, comparing findings in 2011 with those of a methodologically identical study conducted in 1996 by Philip et al. ${ }^{7}$ The study was performed during the departure for summer vacation, a time when traffic is dense, journeys are long and accidents are high.

We found that drivers in 2011 had shortened their overall sleep time during week days, weekends and holidays, and also had a reduced estimation of sleep need compared to drivers in 1996, which led to an apparent reduction in sleep debt the night before the trip but raises the possibility that drivers are chronically short of sleep. This reduction in subjectively reported and objectively recorded sleep time in recent years confirms findings in other studies ${ }^{17} 18$ and may be associated to the demands of work, travel time and leisure activities. ${ }^{3} 19$ Sleeping $<6-7$ hours per night is a risk factor for motor vehicle accidents. ${ }^{3}{ }^{4}$ We found that the duration of sleep the night before travel was similar to regular sleep times, implying that messages concerning the importance of avoiding acute sleep deprivation before setting out had been effective. However, drivers are now chronically sleep deprived, despite awareness of the link between sleepiness, sleep restriction and poor sleep hygiene. ${ }^{20}$ Reduced performance during night driving is well known to be a cause of accidents ${ }^{72}$ and was thus also targeted by road safety campaigns. We found that fewer drivers in 2011 set off between midnight and 06:00 than in 1996.

Sleepiness at the wheel is an important factor contributing to traffic-related morbidity and mortality. ${ }^{1} 222$ Self-reported driving while sleepy is a powerful predictor 
Table 2 Sleep and wake characteristics

\begin{tabular}{|c|c|c|c|c|}
\hline Variables & $\begin{array}{l}1996 \\
N=2197 \\
N(\%)\end{array}$ & $\begin{array}{l}2011 \\
N=3558 \\
N(\%)\end{array}$ & Standardisation* & p Value \\
\hline Duration of sleep on week days & & & $\%$ & $<0.0001$ \\
\hline Less than 7 hours & 209 (10.4) & $584(16.4)$ & 16.9 & \\
\hline 7 and 8 hours $59 \mathrm{~min}$ & $1338(66.7)$ & 2268 (63.8) & 64.2 & \\
\hline 9 hours and more & 460 (22.9) & 704 (19.8) & 18.9 & \\
\hline Duration of sleep on week-end & & & $\%$ & $<0.0001$ \\
\hline less than 7 hours & $84(1.2)$ & $225(6.3)$ & 7.4 & \\
\hline 7 and 8 hours $59 \mathrm{~min}$ & $696(34.7)$ & $1461(41.1)$ & 39.8 & \\
\hline 9 hours and more & $1226(61.1)$ & $1868(52.6)$ & 52.8 & \\
\hline Subjective optimal sleep duration & & & minutes & $<0.0001$ \\
\hline Mean $\pm S D$ & $458( \pm 73)$ & $436( \pm 69)$ & 435 & \\
\hline Hours of optimal sleep & & & $\%$ & $<0.0001$ \\
\hline 6 hours & $285(14.2)$ & 782 (22.0) & 23.4 & \\
\hline 6 hours and $1 \mathrm{~min}$ and 7 hours & $508(25.3)$ & $1053(29.6)$ & 28.6 & \\
\hline 7 hours and $1 \mathrm{~min}$ and 8 hours & $825(41.1)$ & 1424 (40.0) & 39.7 & \\
\hline More than 8 hours & $389(19.4)$ & $299(8.4)$ & 8.4 & \\
\hline Duration of sleep at day-1 & & & $\%$ & NS \\
\hline Less than 7 hours & $585(29.2)$ & $963(27.1)$ & 28.9 & \\
\hline 7 and 8 hours $59 \mathrm{~min}$ & $840(41.8)$ & $1650(46.4)$ & 42.9 & \\
\hline 9 hours and more & $582(29.0)$ & 944 (26.5) & 28.2 & \\
\hline Daytime nap & & & $\%$ & $<0.01$ \\
\hline No & $1710(85.2)$ & $2837(79.7)$ & 80.8 & \\
\hline Yes & 297 (14.8) & 721 (20.3) & 18.4 & \\
\hline Restorative sleep & & & $\%$ & $<0.05$ \\
\hline Never or less than once a week & $121(6.0)$ & $306(8.6)$ & 8.5 & \\
\hline 1-2 days a week & $154(7.7)$ & $252(7.1)$ & 7.2 & \\
\hline 3 or more days a week & 1732 (86.3) & 3000 (84.3) & 84.3 & \\
\hline Bedtimes varying by more than 2 hours & & & $\%$ & $<0.0001$ \\
\hline Never or less than once a week & 1267 (63.2) & $2754(77.4)$ & 73.4 & \\
\hline $1-2$ days a week & $582(29.0)$ & $573(16.1)$ & 19.1 & \\
\hline 3 or more days a week & $157(7.8)$ & $231(6.5)$ & 7.6 & \\
\hline Sleepy during the daytime (BNSQ) & & & $\%$ & $<0.0001$ \\
\hline Never or less than once a week & $1849(92.1)$ & 2701 (75.9) & 75.7 & \\
\hline $1-2$ days a week & $90(4.5)$ & 439 (12.3) & 12.8 & \\
\hline 3 or more days a week & $68(3.4)$ & $418(11.8)$ & 11.4 & \\
\hline Snoring (BNSQ) & & & $\%$ & $<0.0001$ \\
\hline Never or less than once a week & $1127(56.2)$ & $1173(43.7)$ & 47.3 & \\
\hline $1-2$ days a week & $270(13.5)$ & 342 (12.7) & 12.4 & \\
\hline 3 or more days a week & 609 (30.3) & $1169(43.6)$ & 40.3 & \\
\hline Apnoeas (BNSQ) & & & $\%$ & $<0.01$ \\
\hline Never or less than once a week & $1888(94.1)$ & 2636 (91.9) & 91.5 & \\
\hline 1-2 days a week & $51(2.5)$ & $80(2.8)$ & 3.1 & \\
\hline 3 or more days a week & $68(3.4)$ & $151(5.3)$ & 5.4 & \\
\hline
\end{tabular}

*Standardisation: The standardisation column represents the rate and average that will be found if the 2011 drivers had the same distribution than the 1996 population according to age, sex and driving distance.

BNSQ, Basic Nordic Sleep Questionnaire; NS, not significant.

of serious road traffic accidents suggesting that driver's awareness of their sleepiness while driving is not sufficient to prevent them having a serious road traffic accident. ${ }^{1}$ Our results suggest that drivers in 2011 are chronically sleep-deprived and thus more likely to be sleepy at the wheel than drivers in 1996. This is supported by the finding that Epworth sleepiness scores $>15$ (indicating severe sleepiness) were found in over twice as many drivers in 2011 compared to 1996.
Scores on visual analogue scale measurements of sleepiness at the moment of the interview were similar in 1996 and 2011. This may be due to the fact that drivers in 1996 were acutely sleep deprived and those in 2011 were chronically sleep deprived. Chronic sleep restriction has been shown to be associated with a lower increase in subjective sleepiness than acute sleep restriction $^{23} 24$ which leads chronically sleep deprived drivers to underestimate their sleepiness. Drivers who 
Table 3 Sleepiness at the wheel

\begin{tabular}{|c|c|c|c|c|}
\hline Variables & $\begin{array}{l}1996 \\
N=2197 \\
N(\%)\end{array}$ & $\begin{array}{l}2011 \\
N=3558 \\
N(\%)\end{array}$ & Standardisation* & p Value \\
\hline \multicolumn{3}{|l|}{ Sleepiness-related driving accident } & $\%$ & $<0.0001$ \\
\hline Never & $1502(75.0)$ & $2150(60.4)$ & 62.4 & \\
\hline Sleepiness not interfering with driving & $320(16.0)$ & $764(21.5)$ & 20.5 & \\
\hline Sleepiness interfering with driving & $65(3.2)$ & $89(2.5)$ & 2.5 & \\
\hline Sleepiness requiring the driver to stop & $112(5.6)$ & $499(14.0)$ & 13.1 & \\
\hline Sleepiness leading to a near-miss accident & $4(0.2)$ & $56(1.6)$ & 1.4 & \\
\hline \multicolumn{4}{|c|}{$\begin{array}{l}\text { Visual analogue scales at the time of the interview ( } 0=\text { very sleepy à } 10=\text { not at all } \\
\text { sleepy) }\end{array}$} & NS \\
\hline Mean $\pm S D$ & $7.8( \pm 1.7)$ & $7.7( \pm 1.8)$ & 7.7 & \\
\hline \multicolumn{3}{|l|}{ EPWORTH sleepiness score } & $\%$ & $<0.01$ \\
\hline$<11$ & $1811(90.2)$ & $3202(90.0)$ & 89.4 & \\
\hline $11-14$ & $181(9.0)$ & $293(8.2)$ & 8.5 & \\
\hline$\geq 15$ & $15(0.8)$ & $63(1.8)$ & 2.1 & \\
\hline
\end{tabular}

*Standardisation: The standardisation column represents the rate and average that will be found if the 2011 drivers had the same distribution than the 1996 population according to age, sex and driving distance.

NS, not significant.

\section{Table 4 The trip and consumptions}

\begin{tabular}{|c|c|c|c|c|}
\hline Variables & $\begin{array}{l}1996 \\
N=2197\end{array}$ & $\begin{array}{l}2011 \\
N=3558\end{array}$ & Standardisation* & p Value \\
\hline Number of changes of driver since de beginning of the trip & & & & NS \\
\hline Mean $\pm S D$ & $0.19 \pm 0.60$ & $0.23 \pm 0.61$ & 0.27 & \\
\hline Stops since the beginning of the trip & & & & $<0.0001$ \\
\hline Mean \pm SD & $2.70 \pm 1.64$ & $2.16 \pm 1.26$ & 2.31 & \\
\hline Total duration of stops & & & & $<0.0001$ \\
\hline Mean $\pm S D$ & $174 \pm 384$ & $61 \pm 144$ & 78.5 & \\
\hline Sleep during stops & & & $\%$ & $<0.0001$ \\
\hline No & $1744(86.9)$ & $3358(94.4)$ & 93.2 & \\
\hline Yes & $263(13.1)$ & $200(5.6)$ & 6.8 & \\
\hline Sleeping as a passenger & & & $\%$ & NS \\
\hline No & $1898(94.6)$ & $3384(95.1)$ & 93.8 & \\
\hline Yes & $108(5.4)$ & $174(4.9)$ & 6.2 & \\
\hline Number of cans of caffeinated drink/cups of coffee or tea per day & & & & $<0.0001$ \\
\hline Mean \pm SD & $2.8(2.4)$ & $3.5(2.8)$ & 3.6 & \\
\hline Do you use sleeping pills at least once a week? & & & & NS \\
\hline Yes & $92(4.6)$ & $164(4.6)$ & 3.5 & \\
\hline No & $1915(95.4)$ & $3394(95.4)$ & 96.5 & \\
\hline Do you use awakening medications at least once a week? & & & & $<0.01$ \\
\hline Yes & $27(1.4)$ & $13(0.4)$ & 0.4 & \\
\hline No & $1980(98.6)$ & $3545(99.6)$ & 99.6 & \\
\hline Did you use awakening medications during this trip? & & & & $<0.01$ \\
\hline Yes & $20(1.0)$ & $10(0.3)$ & 0.2 & \\
\hline No & $1987(99.0)$ & $3548(99.7)$ & 99.8 & \\
\hline Do you smoke & & & & $<0.0001$ \\
\hline Yes & $674(33.6)$ & $781(22.0)$ & 22.0 & \\
\hline Non & $1333(66.4)$ & $2777(78.0)$ & 78.0 & \\
\hline
\end{tabular}

*Standardisation: The standardisation column represents the rate and average that will be found if the 2011 drivers had the same distribution than the 1996 population according to age, sex and driving distance.

underestimate sleepiness may continue to drive and place themselves at a higher risk of NMA. The number of drivers who had a NMA due to sleepiness was seven times higher in 2011 than in 1996. NMA have been shown to be associated with accidents ${ }^{25}$ and thus this increase in sleepiness at the wheel linked NMA translates into an increased risk for sleep-related accidents. NMA have been found to be related to non-restorative sleep ${ }^{11}$ and it is noteworthy that drivers in 2011 were more likely to suffer from non-restorative sleep, from snoring 
Table 5 Time of departure

\begin{tabular}{|c|c|c|c|c|}
\hline \multirow[b]{2}{*}{ Time of departure } & \multicolumn{2}{|l|}{1996} & \multicolumn{2}{|l|}{2011} \\
\hline & $n$ & Per cent & $n$ & Per cent \\
\hline 00:00-05:59 & 320 & 15.9 & 302 & 8.5 \\
\hline 06:00-11:59 & 1116 & 55.6 & 2137 & 60.2 \\
\hline $12: 00-17: 59$ & 488 & 24.3 & 1072 & 30.2 \\
\hline 18:00-23:59 & 83 & 4.1 & 38 & 1.1 \\
\hline
\end{tabular}

and from respiratory pauses than in 1996, which raises the possibility that more drivers suffered from sleep-related pathology. Sleep apnoea is associated with non-restorative sleep, snoring and increased sleepiness and has been shown to increase the frequency of falling asleep while driving. ${ }^{20}$ Current road safety campaigns encourage drivers to rest and also to take a nap during rest breaks and napping during breaks (although not the number of breaks) increased between 1996 and 2011. The increases in consumption of caffeinated drinks in 2011 may reflect attempts by drivers to normalise their vigilance, but may be counterproductive, as regular high caffeine consumption can impact sleep quality.

\section{Limitations of the study}

Drivers were interviewed between 8:00 and 20:00, as this is the period of highest traffic volume on the highway. However, this time window may be responsible for an underestimate of the frequency of sleep-deprived car drivers, as we have no information on the drivers who passed through the toll booths during the night. Despite this we found twofold fewer drivers beginning their trip between midnight and 8:00, reflecting a real change in driving habits.

The population of both studies is slightly different and the most striking differences were the following:

Driving distance and driving duration for the actual driver were shorter in 2011 than in 1996. The interviews were performed in different regions of France, in the centre of France in the present study and in the West of France in 1996 and this geographical difference can explain the small differences in driving distance. The interviews were performed in different regions of France, in the centre of France in the present study and in the South-West of France in 1996 and this geographical difference can explain the small differences in driving distance. However, both studies were performed on motorways located away from big cities, with similar traffic densities especially during the summer vacation period as drivers head to the coast. In addition, driving distances (mean $377 \mathrm{~km}$ in 1996 and $337 \mathrm{~km}$ in 2001) show that most drivers did not start their journey in the region of the survey. Statistical standardisation was performed to homogenise the populations. The total travel distance was longer in 2011 although the driving distance was shorter which is due to the fact that fewer drivers were driving alone compared to 1996. Driving was often shared, reducing each driver's time at the wheel.
Slightly more women were driving in 2011 than in 1996, and there were fewer single drivers. Driving alone, does not allow drivers to share driving, which could increase the importance of the effect of distance on fatigue. Both the reduction in single drivers and the reduction in the number of drivers beginning their trip at night may be linked to road safety messages which have encouraged drivers to share driving and to limit night driving.

Fifteen years separate the two studies and in order to have a precise barometer of driver's behaviour it would be preferable to perform a similar study every 5 years in order to identify modifications of behaviour and target road safety campaigns more accurately. Our study was performed in 1996 and 2011: road traffic campaigns continue and it is likely that driver behaviour has further evolved since our data were collected. Further studies are planned.

\section{Comments}

In conclusion the present study shows that driver's behaviour has evolved in the 15 years that separate the two studies, with more attention being paid to sleep prior to a trip and avoidance of middle of the night driving. However, in comparison to drivers in 1996, drivers in 2011 suffer from chronic sleep deprivation leading to increases in sleepiness at the wheel even if they are less sleep deprived the night before they set off. In order to further study the evolution of driver's behaviour over time and to evaluate the effectiveness of safety campaigns repeating the study at shorter intervals would identify modifications of behaviour and target road safety campaigns more accurately.

\section{Author affiliations}

${ }^{1}$ Sleep Unit, EA4047, Department of Physical Medicine and Rehabilitation, Assistance Publique des Hôpitaux de Paris (AP-HP), Raymond Poincare Hospital, Garches, France

${ }^{2}$ INSERM CIC1429, APHP, Hôpital Raymond Poincaré, Garches, France ${ }^{3}$ Department of Pediatrics Physical Medicine and Rehabilitation, AP-HP, Raymond Poincare Hospital, Garches, France

${ }^{4}$ CNRS USR 3413 SANPSY "Sommeil, Attention et Neuropsychiatrie ", Bordeaux, France

${ }^{5}$ ISPED, Bordeaux Population Health Research Centre INSERM U1219-, University of Bordeaux, Bordeaux, France

${ }^{6}$ Injury Epidemiology, Transport, Occupation, Bordeaux Population Health Research Centre INSERM U1219-, Bordeaux, France

Acknowledgements The authors are thankful to Ms Bernadette Moreau from the "Fondation Vinci Autoroutes pour une conduite responsable" for her help, to the highway patrol ("la Gendarmerie National"), to ALIX RIS society for their technical support and the elaboration of the iPAD program, and to I'Université de Versailles Saint Quentin en Yvelines for their support in engaging students.

Contributors MAQ-S, FB, SH, JT, RS-Q, PS, BC, JCM, EL and PP agree with the manuscript's results and conclusions. MAQ-S, FB, SH, JT and PP designed the experiments/the study. MAQ-S, FB, SH, RS-Q, PS, BC, JCM, EL and $P P$ analysed the data. MAQ-S, FB, JT and RSQ collected the data. MAQ-S wrote the first draft of the paper. MAQ-S, SH, RS-Q, FB, PS and PP contributed to the writing of the paper.

Funding The study was funded by a grant from "Vinci Fondation Vinci Autoroutes pour une conduite responsable".

Competing interests None declared. 
Ethics approval Comité Ethique de Saint Germain en Laye.

Provenance and peer review Not commissioned; externally peer reviewed.

Data sharing statement No additional data are available.

Open Access This is an Open Access article distributed in accordance with the Creative Commons Attribution Non Commercial (CC BY-NC 4.0) license, which permits others to distribute, remix, adapt, build upon this work noncommercially, and license their derivative works on different terms, provided the original work is properly cited and the use is non-commercial. See: http:// creativecommons.org/licenses/by-nc/4.0/

\section{REFERENCES}

1. Nabi H, Guéguen A, Chiron $M$, et al. Awareness of driving while sleepy and road traffic accidents: prospective study in GAZEL cohort. BMJ 2006;333:75.

2. Connor J, Norton R, Ameratunga S, et al. Driver sleepiness and risk of serious injury to car occupants: population based case-control study. BMJ 2002;324:1125.

3. Stutts JC, Wilkins JW, Scott Osberg J, et al. Driver risk factors for sleep-related crashes. Accid Anal Prev 2003;35:321-31.

4. Herman J, Kafoa B, Wainiqolo I, et al. Driver sleepiness and risk of motor vehicle crash injuries: a population-based case-control study in Fiji (TRIP 12). Injury 2014;45:586-91.

5. ONISR. La securité routière en France. Bilan Année 2010. Paris: ONISR, 2010

6. Tefft BC. Prevalence of motor vehicle crashes involving drowsy drivers, United States, 1999-2008. Accid Anal Prev 2012;45:180-6.

7. Philip P, Taillard J, Guilleminault C, et al. Long distance driving and self-induced sleep deprivation among automobile drivers. Sleep 1999;22:475-80.

8. Association des Sociétés Françaises d'Autoroutes AFSA. Evolution du facteur Fatigue, Hypovigilance; Endormissement entre 1997 et 2005. Paris: AFSA, 2010

9. Larue GS, Rakotonirainy A, Pettitt AN. Driving performance impairments due to hypovigilance on monotonous roads. Accid Anal Prev 2011;43:2037-46

10. Garbarino S, Nobili L, Beelke M, et al. The contributing role of sleepiness in highway vehicle accidents. Sleep 2001;24:203-6.

11. Quera Salva MA, Barbot F, Hartley S, et al. Sleep disorders, sleepiness, and near-miss accidents among long-distance highway drivers in the summertime. Sleep Med 2014;15:23-6.
12. Johns MW. Reliability and factor analysis of the Epworth Sleepiness Scale. Sleep 1992;15:376-81.

13. Partinen M, Gislason T. Basic Nordic Sleep Questionnaire (BNSQ): a quantitated measure of subjective sleep symptoms. J Sleep Res 1995;4(Suppl 1):150-5.

14. Smirne S, Palazzi S, Zucconi M, et al. Habitual snoring as a risk factor for acute vascular disease. Eur Respir J 1993;6: 1357-61.

15. Young T, Palta M, Dempsey J, et al. The occurrence of sleep-disordered breathing among middle-aged adults. $N$ Engl $J$ Med 1993;328:1230-5.

16. von Elm E, Altman DG, Egger M, et al. The Strengthening the Reporting of Observational Studies in Epidemiology (STROBE) Statement: guidelines for reporting observational studies. Int J Surg 2014;12:1495-9.

17. Knutson KL, Van Cauter E, Rathouz PJ, et al. Trends in the prevalence of short sleepers in the USA: 1975-2006. Sleep 2010;33:37-45.

18. Kronholm E, Partonen T, Laatikainen T, et al. Trends in self-reported sleep duration and insomnia-related symptoms in Finland from 1972 to 2005: a comparative review and re-analysis of Finnish population samples. J Sleep Res 2008;17:54-62.

19. Basner M, Fomberstein KM, Razavi FM, et al. American time use survey: sleep time and its relationship to waking activities. Sleep 2007;30:1085-95.

20. Gonçalves M, Amici R, Lucas R, et al. Sleepiness at the whee across Europe: a survey of 19 countries. J Sleep Res 2015;24:242-53.

21. Verster JC, Taillard J, Sagaspe $P$, et al. Prolonged nocturnal driving can be as dangerous as severe alcohol-impaired driving. J Sleep Res 2011;20:585-8.

22. Liu GF, Han S, Liang DH, et al. Driver sleepiness and risk of car crashes in Shenyang, a Chinese northeastern city: population-based case-control study. Biomed Environ Sci 2003;16:219-26.

23. Philip $P$, Sagaspe $P$, Prague $M$, et al. Acute versus chronic partial sleep deprivation in middle-aged people: differential effect on performance and sleepiness. Sleep 2012;35:997-1002.

24. Van Dongen HPA, Maislin G, Mullington JM, et al. The cumulative cost of additional wakefulness: dose-response effects on neurobehavioral functions and sleep physiology from chronic sleep restriction and total sleep deprivation. Sleep 2003;26:117-26.

25. Powell NB, Schechtman KB, Riley RW, et al. Sleepy driver near-misses may predict accident risks. Sleep 2007;30: 331-42. 